\title{
Opinion clusters in academic and public debates on growth-vs-environment
}

\author{
Stefan Drews ${ }^{1,2}$, Ivan Savin ${ }^{1,3}$ and Jeroen C.J.M. van den Bergh $h^{1,4,5}$
}

October 2018

\begin{abstract}
The debate about the relationship between economic growth and environmental sustainability involves many dimensions as well as much diversity in terminology. While it is often summarized in terms of dichotomous pro- and anti-growth positions, several studies indicate that additional views exist, and that these may differ between experts and the general public. The objective of this paper is to identify and analyze segments of the scientific and general population with distinct views in this respect. To this end, we bring together two data sets: one from a nationally representative survey of the general public of Spain $(N=1,004)$ and another from an international survey of researchers from various disciplinary backgrounds $(N$ = 814). Using latent class analysis, we identify three similar segments in the two samples, labelled as Green growth, Agrowth and Degrowth. Clusters in scientific opinion systematically differ on all main questions, while clusters in public opinion differ only on some issues. Overall, clusters are more consistent, better distinguishable on all constituent dimensions and more polarized in the scientific than public opinion survey. In addition, we find that diverging views on social issues are more strongly associated with distinct clusters in the public opinion sample, and on environmental issues in the scientific opinion sample.
\end{abstract}

Keywords: clustering, growth-vs-environment debate, public opinion, scientific opinion, segmentation.

\footnotetext{
${ }^{1}$ Institute of Environmental Science and Technology, Universitat Autònoma de Barcelona, Spain.

${ }^{2}$ Corresponding author: ICTA-UAB, Edifici Z, UAB Campus, 08193 Bellaterra, Spain; stefan.drews@uab.es, phone: +34-93-5868773.

${ }^{3}$ Graduate School of Economics and Management, Ural Federal University, Yekaterinburg, Russian Federation

${ }^{4}$ ICREA, Barcelona, Spain.

${ }^{5}$ Faculty of Economics and Business Administration \& Institute for Environmental Studies, VU University Amsterdam, the Netherlands.
} 


\section{Introduction}

Various indications suggest that opinions about the relationship between economic growth and environmental sustainability remain divided. An increasing number of studies indicate that growth is not compatible with environmental goals such as climate change mitigation (e.g. Jackson, 2009; Ward et al., 2016). In fact, around 15,000 scientists recently signed a call for humanity to end environmental destruction, which among other things asked to "reassess the role of an economy rooted in growth" (Ripple et al., 2017). Furthermore, although it does not yet translate in much parliamentary debate, there is evidence that politicians from left to right see the need to discuss alternative concepts of growth (Rivera, 2017). In addition, public opinion research indicates that more people prioritize environmental protection over economic growth in many European countries (Drews et al., 2018). These indications show that both scientists and the general public are involved in the debate. Hence, it is relevant to examine to what extent opinions about growth-versus-environment are similar or different between these two populations.

An emerging literature is concerned with understanding public perceptions and attitudes related to this debate. A central research aim is to identify groups in the population that hold distinct views about this issue. The simplest form of grouping is dichotomous, that is, two groups with pro- and anti-growth views. Large-scale surveys such as the World Values Survey or the US Gallup poll capture views on growth-versus-environment by asking a single-item question framed in this way. However, such dichotomization is likely to hide heterogeneity (Kaplowitz et al., 2013; de Mooij and van den Bergh, 2002). Recent assessments of the growth-versus-environment debate have identified three main positions: "green growth", "agrowth" and "degrowth" (van den Bergh and Kallis, 2012). Further concepts and labels such as "sustainable growth", "prosperity without growth", "steady-state economy", "beyond GDP" and "post-growth" demonstrate that the debate is not short of terminology (Jackson 2009; O’Neill 2012; Kubiszewski et al. 2013). This diversity of views 
may be due to the growth debate touching upon many social and cultural issues, such as consumerism, inequality and well-being (Victor and Dolter, 2017).

In any case, it remains unclear whether one can empirically identify a segmentation of opinions about growth-versus-environment that goes beyond the dichotomous pro-/antigrowth framing. The purpose of this paper is to investigate how many segments of the population with distinct views exist, what size they are, and how they differ in terms of sociodemographic and other characteristics. In particular, we are interested to capture opinion clusters by using questions on many dimensions of the growth debate, thus going beyond identifying opinions through single-item questions as in most previous studies based on, for example, the World Values Survey data set.

To achieve this, we draw on clustering (or segmentation) analysis, which has been used extensively in research on environmental attitudes, notably regarding climate change (Hine et al. 2014). For example, a US study has identified six segments of the population with respect to climate change beliefs and behaviors, labeled as: "alarmed", "concerned", "cautious", “disengaged", “doubtful”, and "dismissive" (Maibach et al., 2011). These segments show distinct views, for example, regarding the expression of support for climate policies. However, such studies on climate change perception barely address the relationship with economic growth. A study by Poortinga and Darnton (2016) employed a more multidimensional approach which identified six segments of the population with regard to sustainability: "enthusiasts", "pragmatists", "aspirers", “community focused”, "commentators", and "self-reliant". While it was not the focus of the study, it also included two scales measuring views on growth. These indicate that members of some segments tend to prefer having continued growth and prioritizing the environment over growth at the same time (the "enthusiast"), others have negative views about continued growth and prefer prioritizing the environment (the "pragmatists"), while again other groups have rather mixed views. 
With regard to opinion clusters on growth-versus-environment, we are only aware of two unpublished studies by Tomaselli (2017). The first is based on interviews in Canada exploring mental models about growth and ecological economics. It describes five models or clusters of opinions: "expansionist", "hesitant", “indifferent", "green-leaning" and "concerned". The expansionists believed in indefinite growth and were highly techno-optimistic; the hesitant were unsure or undecided about the existence of limits to growth; the indifferent, greenleaning and concerned all believed in limits to growth, but had different reasonings for their beliefs. A follow-up study by the same author sought to identify these segments in a large Canadian sample $(N=1,001)$. It used 12 Likert items (e.g. "The negative consequences of economic growth are greater than its benefits") in its analysis, which resulted in three clusters: $41 \%$ held attitudes closer to an expansionist worldview (that is, they were optimistic about growth), 23\% held attitudes closer to an ecological worldview (skeptical about indefinite growth and technology), and 36\% were in-between these two segments (no strong opinions about any issue).

It is worthwhile to mention two clustering studies which sampled from two distinct groups in society, notably environmental experts and activists. The first, by Illge and Schwarze (2009), surveyed 196 German-speaking economists and sustainability researchers, asking them 40 sustainability-related questions. They derive a two-cluster solution including “ecological economics" and "open-minded neoclassical environmental economics". Yet, only 2 out of 40 questions explicitly addressed economic growth, and these were not among the questions that contributed to a clear divide - compared to, for example, questions about human behavior or the degree of objectivity of science. The second study drew on 814 participants of the 2014 Degrowth conference in Germany, which included academics as well as practitioners and activists, identified five different groups (Eversberg and Schmelzer 2018). Besides a shared common ground, namely to reject growth for both environmental and social 
justice reasons, the clusters demonstrate substantial diversity, such as regarding everyday environmental practices (e.g., flying, meat consumption) or party politics.

The objective of this paper is to identify and analyze segments of the population with distinct views regarding the growth-versus-environment debate, while testing whether these differ among experts and the general public. For this we use and bring together two data sets (Drews and van den Bergh, 2016/2017): the first is from a nationally representative survey of the general public of Spain $(N=1,008)$, while the second is from an international survey of researchers from various disciplinary backgrounds $(N=814)$. The sample of the scientific survey is distinct from the two previously mentioned ones in the sense that it covers a considerably broader range of academic disciplines (compared to Illge and Schwarze, 2009) and invited views from all growth-vs-environment positions (compared to only degrowth in Eversberg and Schmelzer, 2018). In this way, we not only conduct one of the first segmentation studies on growth-vs-environment, but also contribute to the literature comparing public and scientific opinion, such as on economic (e.g. Blendon et al. 1997; Sapienza and Zingales 2013) and climate issues (Moloney et al., 2014).

\section{Method}

\subsection{Data}

The first data set comes from a survey of the general public of Spain that included 1,004 respondents. It is representative of the general population of Spain in terms of age, gender, income, education and geographical regions. The data was collected in 2014 through an online survey. More details about the survey implementation can be found in Drews and van den Bergh (2016).

The second data set is composed of 814 researchers from a wide range of self-identified academic backgrounds, including economic growth studies, general economics, environmental economics, ecological economics, environmental social sciences, and 
environmental sciences. The data was collected through an international online survey in 2015. Among those invited to participate in the survey were researchers who published articles on growth-versus-environment or who published in journals (e.g. ecological economics) relevant to the topic of interest. More details about the scientific opinion survey can be obtained from Drews and van den Bergh (2017). In line with these two data sets, we later use "Sci" and "Pub" to refer to clusters identified in the scientific and public surveys, respectively.

\subsection{Survey questions}

Both surveys included 16 questions in the form of statements pertaining to the debate on economic growth versus the environment, listed in Table 1. They had identical wordings and were both answered on 7-point Likert scales from 1 (strongly disagree) to 7 (strongly agree). Our segmentation analysis is built on the answers to these 16 questions. In addition, note that respondents in both surveys were informed that the term "economic growth" in all survey questions was defined as GDP growth.

Table 1. Main statements of both surveys serving as input to the cluster analysis

\begin{tabular}{|l|l|}
\hline Statement label & Statement wording \\
\hline Life satisfaction & Continued economic growth is essential for improving people's life satisfaction. \\
\hline Public services & Economic growth is necessary to finance public health and pension systems. \\
\hline Stability & Without economic growth the economy will become less stable. \\
\hline Environmental protection & Economic growth is necessary to finance environmental protection. \\
\hline Full employment & Full employment can be achieved without economic growth. \\
\hline Good life & A 'good life' without economic growth is possible. \\
\hline Energy rebound & $\begin{array}{l}\text { Energy savings due to technological advances are partly undone by further economic } \\
\text { growth. }\end{array}$ \\
\hline Environmental damage & Economic growth always harms the environment. \\
\hline Development space & $\begin{array}{l}\text { In view of limited natural resources, rich countries may have to give up their economic } \\
\text { growth to assure that all poor people in the world can reach a fair standard of living. }\end{array}$ \\
\hline Techno-fix & Technology can solve all environmental problems associated with economic growth. \\
\hline Recovery & Future economic growth will recover and again be as high as in the past. \\
\hline Post-materialism & $\begin{array}{l}\text { Economic growth raises incomes which in turn make people care more about the } \\
\text { environment. }\end{array}$ \\
\hline Excessive political attention & Politicians are too concerned about economic growth. \\
\hline Income inequality & $\begin{array}{l}\text { Making the income distribution more equal should get a higher priority than economic } \\
\text { growth. }\end{array}$ \\
\hline Flawed welfare measure & The GDP is a flawed measure of social welfare. \\
\hline Governmental control & Economic growth can be controlled by the government. \\
\hline
\end{tabular}


There is one minor difference between the designs of the two surveys. Whereas in the scientific opinion sample respondents could provide a non-response by clicking "no opinion" or not answering a question, in the public opinion survey there was no such option and respondents instead were forced to provide an answer. This difference explains a substantial number of missing observations in the scientific survey, regarding the 16 questions about the growth-vs-environment debate as well as other variables. In particular, out of 814 respondents 143 have missing responses on one or more of the 16 questions. To make sure that dropping these observations does not bias our sample, we conducted a Kolmogorov-Smirnov test (with the null hypothesis that the two samples are drawn from the same distribution) and a Wilcox rank sum test (equivalent to the Mann-Whitney test, with the null hypothesis that the two distributions differ in terms of a location shift). The results demonstrate that we can neither reject the null hypotheses nor detect any difference between the two samples (see Table A1 in the Appendix). In Figure A1 and A2 in the Appendix we illustrate how the two samples compare in terms of the distributions over the 16 main questions from Table 1 and additional questions from Table 2 .

There are six additional variables that are nearly identical in both surveys. Three of them are related to economic growth and will be used in the analysis to characterize and validate the emerging clusters. Moreover, there are three socio-demographic variables that are comparable in both surveys, namely gender, age and political orientation. All question wordings and codings of these six additional variables can be found in Table 2. Note that for the few cases where question wordings or codings slightly differ between surveys, we indicate this in the table by providing both variations. 
Table 2. Question wordings and codings of additional survey items

\begin{tabular}{|c|c|c|}
\hline Variable & Wording and response options & Coding \\
\hline \multicolumn{3}{|c|}{ Questions about economic growth } \\
\hline $\begin{array}{l}\text { Favored } \\
\text { growth- } \\
\text { environment } \\
\text { strategy }\end{array}$ & $\begin{array}{l}\text { Here are several positions on the relation between economic growth and the } \\
\text { environment. Which of them is closest to your own opinion? Public policy in rich } \\
\text { industrialized countries should... } \\
\text { Position 1: ...further pursue economic growth in spite of its environmental impacts } \\
\text { Position 2: ...further pursue economic growth. There are many ways to make economic } \\
\text { growth compatible with environmental sustainability } \\
\text { Position 3: ...ignore economic growth as a policy aim, that is, be completely neutral } \\
\text { about growth. This will amplify the policy spectrum to combine well-being and } \\
\text { environmental sustainability goals } \\
\text { Position 4: ...stop pursuing economic growth. Production and consumption need to be } \\
\text { downscaled in an equitable way to achieve environmental sustainability. }\end{array}$ & 1 to 4 \\
\hline $\begin{array}{l}\text { Belief in end of } \\
\text { growth }\end{array}$ & $\begin{array}{l}\text { Scientific opinion: Roughly speaking, when do you think economic growth in rich } \\
\text { industrialized countries will permanently come to an end? } \\
\text { Public opinion: Roughly speaking, when do you think economic growth in rich } \\
\text { industrialized countries will come to an end? } \\
\text { In less than } 10 \text { years; } 10-25 \text { years; } 25-50 \text { years; } 50-100 \text { years; more than } 100 \text { years; } \\
\text { never }\end{array}$ & $\begin{array}{l}0 \text { (never) } \\
\text { versus } 1 \text { (all } \\
\text { other } \\
\text { response } \\
\text { options) }\end{array}$ \\
\hline $\begin{array}{l}\text { Favored growth } \\
\text { rate }\end{array}$ & $\begin{array}{l}\text { Scientific opinion: Which average annual rate of economic growth should governments } \\
\text { of rich industrialized countries aim for in the next decade? } \\
\text { Public opinion: What rate of economic growth should the government of a rich } \\
\text { industrialized country aim for? }\end{array}$ & $\begin{array}{l}\text { Growth rate } \\
(\%)\end{array}$ \\
\hline \multicolumn{3}{|c|}{ Sociodemographic variables } \\
\hline $\begin{array}{l}\text { Political } \\
\text { orientation }\end{array}$ & $\begin{array}{l}\text { Public opinion: In politics people sometimes talk of "left" and "right". Where would } \\
\text { you place yourself on this scale, where } 1 \text { means the left and } 9 \text { means the right? } \\
\text { Scientific opinion: In politics people sometimes talk of "left" and "right" (or "liberal" } \\
\text { and "conservative" in the US). Where would you place yourself on the following scale? }\end{array}$ & $\begin{array}{l}\text { Pub: } 1 \text { (left) } \\
\text { to } 9 \text { (right) } \\
\text { Sci: } 1 \text { (very } \\
\text { left) to } 7 \\
\text { (very right) }\end{array}$ \\
\hline Gender & - & $\begin{array}{l}0 \text { (male) to } 1 \\
\text { (female) }\end{array}$ \\
\hline Age & - & $\begin{array}{l}\text { Number in } \\
\text { years }\end{array}$ \\
\hline
\end{tabular}

\subsection{Analytical strategy}

Methods of segmentation research aim to identify clusters of individuals with similar opinions

on a range of related questions. Their objective is to simultaneously achieve smallest within- 
group heterogeneity and largest between-group differences. Traditionally, clustering techniques are divided into two broad categories: hierarchical and non-hierarchical ones (Hine et al., 2014). Hierarchical clustering involves estimating a matrix of pairwise distances between observations according to some pre-specified distance metric (such as Manhattan or Euclidian distance), which allows the generation of a tree-based representation of the observations (a 'dendrogram'). The clusters are then determined by its examination, balancing height of the fusion on the vertical axis, which serves as a proxy of the dissimilarity between observations, and the number of clusters. Non-hierarchical clustering requires a pre-specified number of clusters, and then allocates individuals in one of them. The most frequently used non-hierarchical methods are K-means and latent class analysis (LCA). K-means randomly allocates centroids (seeds) for the pre-specified (k) clusters and then assigns each individual to the closest centroid (cluster). Subsequently, one iteratively updates the values of the centroids by calculating means of the formed clusters. This continues until the algorithm converges, i.e. once the values of the centroids do not change further.

In the last decade, interest has been rising in the application of another non-hierarchical method, namely LCA (see McCutcheon, 1987). It is known not only as a method of clustering observations, but as a modeling tool for accounting for heterogeneity in data (Vermunt and Magidson, 2004). LCA aims to uncover hidden clusters in data by grouping subjects from multivariate data into "latent classes", i.e. groups with similar, unobservable, membership. It does so using model-based posterior membership probabilities estimated by maximum likelihood estimation. Among the advantages of LCA is the provision of a range of fitness indices (like information criteria) for determining which number of clusters best fits the data and a proven ability to recover true group structures where alternative clustering methods fail (Bacher et al., 2004).

For this reason, we will use LCA from the "poLCA" package in R software (Linzer and Lewis, 2011). In particular, we apply LCA to each of the two surveys separately (Sections 
3.1-3.2), while subsequently we compare the obtained clusters based on a composite index of growth skepticism and separately on all the relevant dimensions (Sections 3.3-3.4). This approach has the advantage of identifying differences between respondents of the two surveys. Instead, pooling the data and performing then a single cluster analysis would not allow us to identify distinct clusters within each population. We will estimate the fitness of distinct numbers of clusters (from one to nine), and make a final decision based on performance in terms of information criteria that maximize model fit and penalize complexity (number of clusters). Since LCA is a stochastic method, we will restart the algorithm 50 times and run it for 3000 iterations, to ensure robustness of convergence and rule out local optima.

\section{Results}

\subsection{Scientific opinion clusters}

We start with defining the appropriate number of clusters. To do so, we consider three commonly used Information Criteria (ICs): consistent Akaike criterion (cAIC), Bayesion criterion (BIC) and adjusted BIC (aBIC). Two ICs (BIC and cAIC) suggest three clusters while the third one (aBIC) points towards 5 clusters (see Figure A3 in the Appendix). Taking into account that BIC has been recommended as the superior measure (Nylund et al., 2007), we decide to use three clusters. This also avoids a more complicated model (of five clusters) which is harder to interpret. Figure 1 shows the resulting three clusters and their distribution with respect to the 16 main questions. Here one can see that taking into account all the questions used, clusters clearly differ, which indicates that there are systematic differences between respondents. We continue by analyzing these differences seen in the visual presentations, but note that we also conducted tests indicating statistically significant differences (Table A2 in the Appendix).

The Green growth Sci cluster (green, 31\% of the sample) represents the researchers with the most favorable views about growth. Its members think that there is sufficient space for 
development, that growth is needed for environmental protection and that it is not always harmful to the environment. In addition, they believe that growth is necessary to improve life satisfaction and do not agree that lowering inequality should be prioritized.

The Degrowth Sci cluster (red, 25\% of the sample) is antagonistic to Green growth Sci cluster, as these researchers have the most critical views about growth. Compared to the other clusters, the relation of growth to the environment is seen to be as skeptical, that is, growth is viewed as damaging the environment and is not considered to be necessary for protecting the environment. This cluster also strongly disagrees with the potential of technology to solve environmental problems. Furthermore, it disagrees strongly with the idea that growth is needed to improve life satisfaction and believes that a good life is possible without growth. Finally, these researchers strongly believe in the limits of development space and that lowering inequality should be prioritized over growth.

The Agrowth Sci cluster (blue, $44 \%$ of the sample) is in-between the two previous ones. While on some issues this cluster is closer to Green growth Sci cluster (namely on opinions regarding development space, energy rebound, excessive political attention and governmental control), on others it is closer to Degrowth Sci cluster (opinions on environmental damage of growth, stability, recovery, public services, good life). On certain issues, namely skepticism regarding whether growth is needed for environmental protection, full employment, life satisfaction and good life, the Agrowth Sci cluster is very much in-between the two other clusters. 


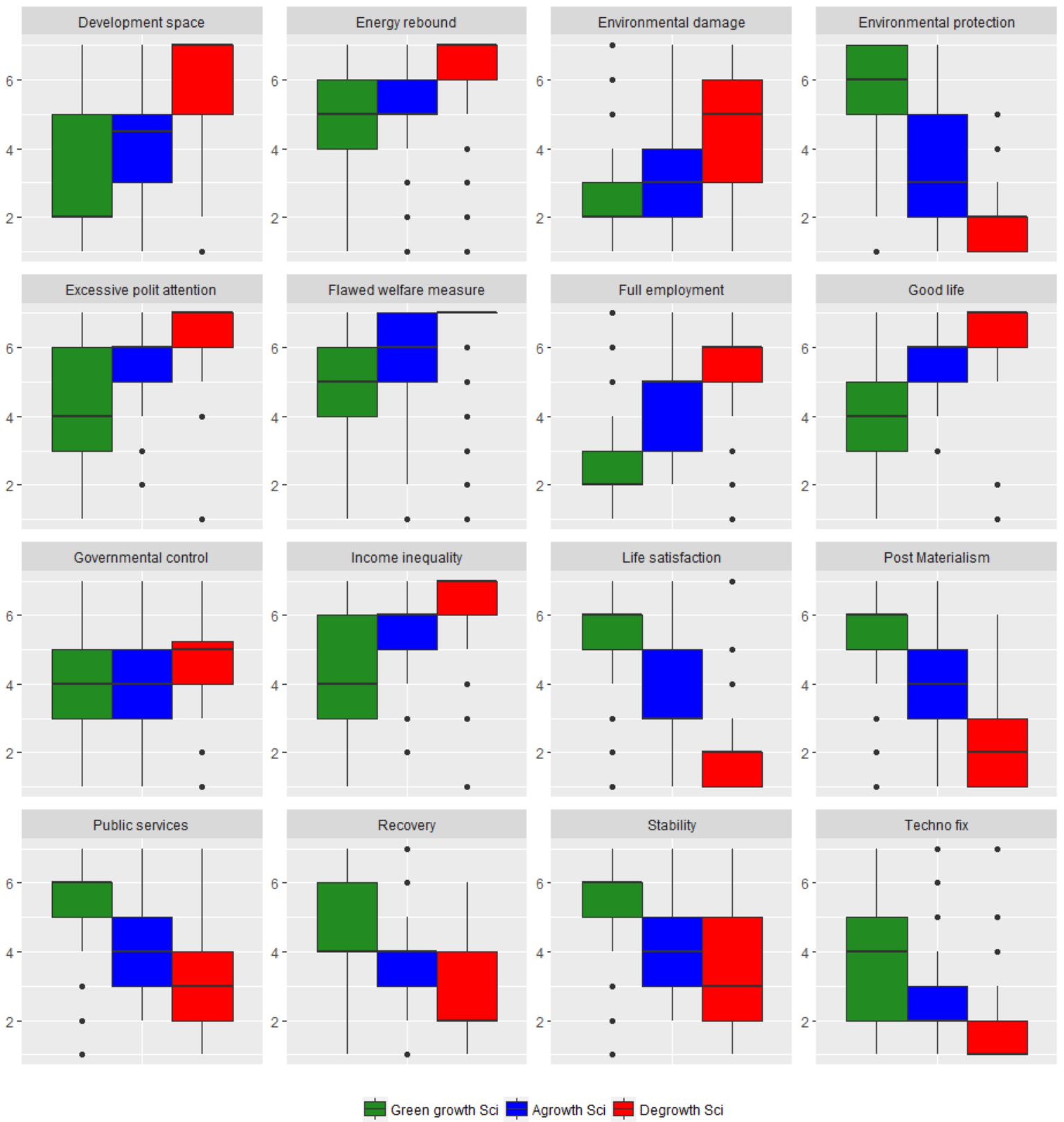

Figure 1. Distribution of responses on the 16 questions regarding growth-vs-environment debate among the three clusters in the scientific opinion survey.

Note: Responses on the Y-axis range from 1 (completely disagree) to 7 (completely agree).

In Figure 2 we can observe how the clusters relate to the three additional variables about growth (complete question wordings are in Table 2). It is noteworthy that the clusters are associated to the preferred growth-environment strategies in a way one might expect based on the literature (van den Bergh and Kallis, 2012). In particular, we find that the Green growth Sci cluster prefers a public policy that combines economic growth and environmental sustainability, assuming that both objectives are compatible (value " 2 " on the Y-axis of the 
second graph in Figure 2). The Agrowth Sci cluster prefers a public policy that ignores economic growth as an objective, making it easier to combine well-being and sustainability (value "3"). The Degrowth Sci cluster prefers a public policy that has the goal of stopping economic growth, meaning a reduction of production and consumption in order to achieve sustainability (value "4”). This result can be seen as a validation of the clustering exercise, as these preferences may capture the essence of each cluster. This result also serves as a justification for the labels used to describe the three clusters in scientific opinion and subsequently in public opinion. In addition, the results show that the Green growth Sci cluster tends to show a belief in never-ending growth (value " 0 " in the first graph of Figure 3), whereas the Agrowth Sci and Degrowth Sci clusters think that growth will come to an end at some point in the future (value "1"). Moreover, the favored growth rate in rich countries decreases steadily from Green growth Sci to Degrowth Sci (graph 3 in Figure 2). These tendencies are confirmed by the multinomial regression analysis shown in Table 3, which includes age, gender and political orientation in addition to the three variables about growth.

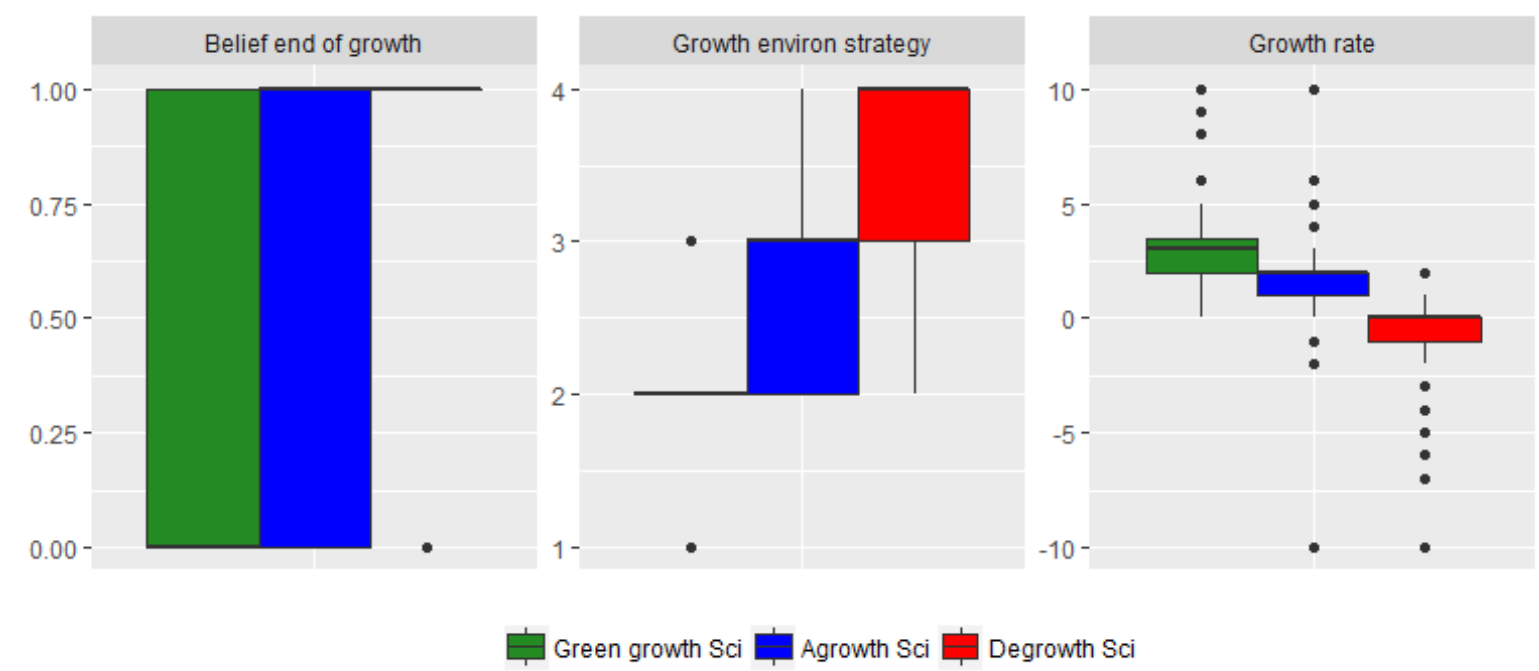

Figure 2. Relating the three scientific clusters to additional variables regarding growth. Note: The units of the Y-axis are explained in Table 2. 
Table 3. Multinomial logit regression analysis of cluster membership and additional survey variables

\begin{tabular}{|c|c|c|c|c|c|}
\hline & \multicolumn{2}{|c|}{ Scientific opinion } & \multicolumn{3}{|c|}{ Public opinion } \\
\hline & Green Growth & Degrowth & Green growth & Degrowth & Indifferent \\
\hline \multirow[t]{2}{*}{ Age } & -0.007 & 0.026 & $0.023^{* * *}$ & -0.006 & $-0.048^{* * *}$ \\
\hline & $(0.014)$ & $(0.023)$ & $(0.007)$ & $(0.008)$ & $(0.012)$ \\
\hline \multirow[t]{2}{*}{ Gender } & 0.238 & -0.432 & $-0.349^{* *}$ & $-0.866^{* * * *}$ & $0.714^{* *}$ \\
\hline & $(0.472)$ & $(0.642)$ & $(0.172)$ & $(0.217)$ & $(0.295)$ \\
\hline \multirow[t]{2}{*}{$\begin{array}{l}\text { Political } \\
\text { orientation }\end{array}$} & $0.400^{* * *}$ & $-1.043^{* * *}$ & -0.053 & $-0.290^{* * *}$ & 0.042 \\
\hline & $(0.141)$ & $(0.340)$ & $(0.043)$ & $(0.061)$ & $(0.066)$ \\
\hline \multirow{2}{*}{$\begin{array}{l}\text { Belief end of } \\
\text { growth }\end{array}$} & $-1.002^{* * *}$ & 1.105 & $-0.698^{* * *}$ & -0.387 & $-0.583^{*}$ \\
\hline & $(0.376)$ & $(0.912)$ & $(0.184)$ & $(0.245)$ & $(0.299)$ \\
\hline \multirow{2}{*}{$\begin{array}{l}\text { Growth } \\
\text { environment } \\
\text { strategy }\end{array}$} & $-2.085^{* * *}$ & $1.139^{* *}$ & $-0.274^{* *}$ & $0.635^{* * *}$ & 0.106 \\
\hline & $(0.431)$ & $(0.519)$ & $(0.121)$ & $(0.128)$ & $(0.172)$ \\
\hline \multirow{2}{*}{$\begin{array}{l}\text { Favored growth } \\
\text { rate }\end{array}$} & $0.460^{* * *}$ & $-1.648^{* * *}$ & 0.034 & $-0.295^{* * *}$ & 0.108 \\
\hline & $(0.122)$ & $(0.364)$ & $(0.048)$ & $(0.056)$ & $(0.074)$ \\
\hline \multirow[t]{2}{*}{ Constant } & $2.664^{*}$ & -2.708 & 0.042 & 0.380 & -0.833 \\
\hline & $(1.377)$ & (1.959) & $(0.538)$ & $(0.627)$ & $(0.832)$ \\
\hline Akaike Inf. Crit. & 326.067 & 326.067 & $1,949.082$ & $1,949.082$ & $1,949.082$ \\
\hline
\end{tabular}

Note: Agrowth is the reference group in scientific and public opinion. P-values: ${ }^{*} \mathrm{p}<0.1$; ${ }^{* *} \mathrm{p}<0.05 ;{ }^{* * *} \mathrm{p}<0.01$.

\subsection{Public opinion clusters}

Now we apply the same sequence of steps to the public opinion survey available. One of the first important findings here is that $\mathrm{AIC}$ and BIC indicate that the optimal number of clusters is not three (like for scientific survey) but four (see Figure A4 in the Appendix). We proceed using this number of clusters.

We consider the distribution of responses with respect to the 16 questions regarding the growth-vs-environment debate used for clustering, as shown in Figure 3. In contrast to the scientific opinion survey the resulting clusters largely overlap for the majority of dimensions, 
reflected by the same median response, and sometimes even further moments (quantiles). The clearest examples are opinions on energy rebound, environmental damage, and governmental control, and to a lesser degree also development space, flawed welfare measure and techno fix. This may indicate the fact that respondents have strong differences in opinion only on few issues, such as life satisfaction and good life. This raises some doubts about the labelling of the clusters. However, as we see similarity with patterns in scientific opinion, we use the same labels as before to describe three out of the four clusters. 

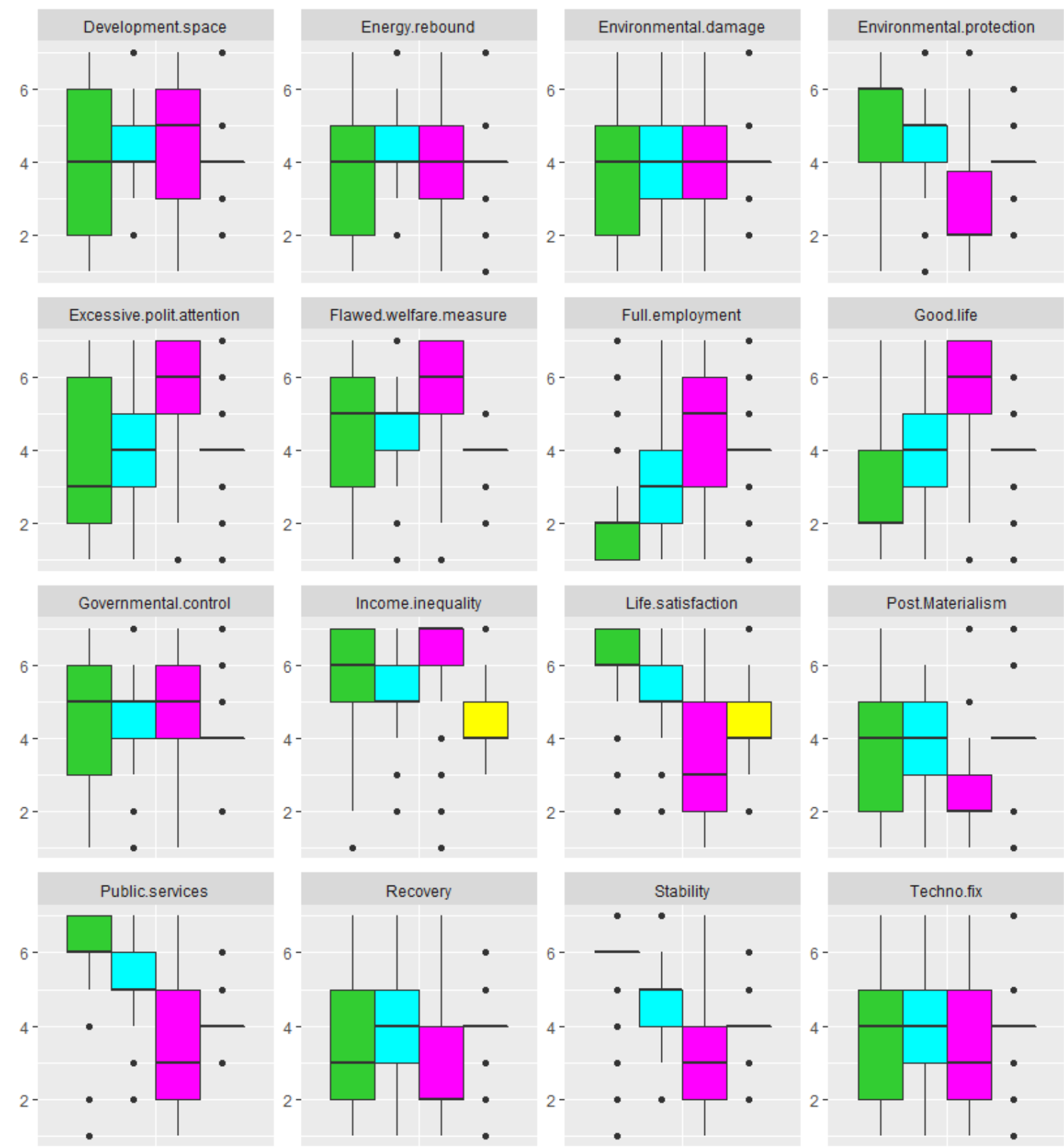

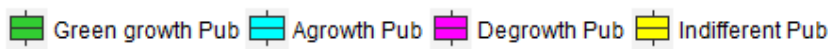

Figure 3. Distribution of responses on the 16 questions regarding the growth-vs-environment debate among the four clusters in the public opinion survey.

Note: Responses on the Y-axis range from 1 (completely disagree) to 7 (completely agree).

The Indifferent Pub cluster (yellow, 10\% of the sample) shows, consistent with its label, surprisingly little variation: over $99 \%$ of responses have the same value ("4" - neither disagree nor agree) for 14 out of 16 questions. This may indicate that people are indifferent, undecided, neutral or lack awareness about the issue (Sturgis et al. 2014). Given that the 
survey did not have a non-response option, these people might have chosen to not respond if this option had been available. It is impossible here to give a conclusive answer as to the underlying motivation of these responses. We decide to keep this cluster as it may otherwise lead to a misrepresentation of public opinion.

The Green growth Pub cluster (green, 29\% of the total sample) shows overall the most positive views about growth. For example, people in this cluster agree most to the statements that growth is necessary to improve life satisfaction and to finance environmental protection, and they disagree most with the ideas that "a good life is possible without growth" or the excessive political attention given to growth.

The Degrowth Pub cluster (magenta, $18 \%$ of the sample) has overall the most negative views about growth. Compared to the other clusters, it reflects agreement with the idea of a good life without growth, that growth is given excessive political attention, and that full employment is possible without growth. It also indicates disagreement with growth being necessary for life satisfaction, environmental protection, economic stability and public services. Compared to the other clusters, it disagrees that people will become more environmentally concerned with rising incomes (post-materialism) and that environmental problems can be fixed with technology.

The Agrowth Pub cluster (turquoise, $43 \%$ of the sample) falls between the Green growth Pub and Degrowth Pub clusters on some questions, such as about the good life. However, overall one can observe that on several issues people in this cluster tend to be more similar to the Green growth Pub than to the Degrowth Pub cluster (environmental protection, excessive political attention, full employment, public services, post-materialism, economic stability).

Figure 4 shows how clusters are associated with further survey questions about growth. With respect to the growth-environment strategy, we find that the Degrowth Pub cluster prefers ignoring (but not stopping) economic growth (value " 3 " in the second graph of Figure 4, whereas all other clusters prefer continuing with growth while combining it with 
sustainability (value "2"). These results are less consistent compared with the scientific opinion survey. However, when we consider the inter-quartile ranges, we see the Agrowth and Degrowth Pub clusters extend to ignoring (value 3) and stopping (4) growth, respectively. Moreover, Degrowth Pub has a lower (but not a zero) desired growth rate for rich countries. There are no differences in terms of beliefs about an end to economic growth in the future.

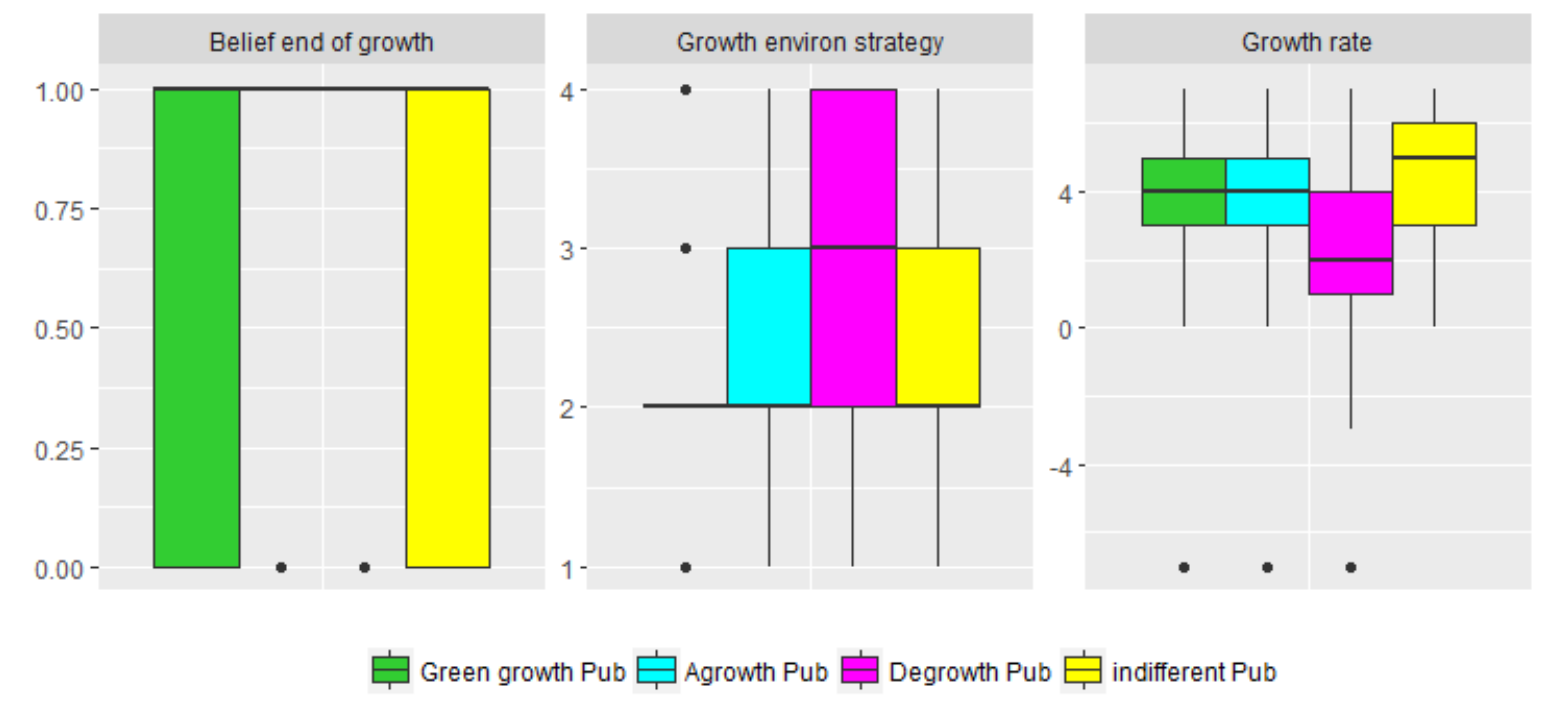

Figure 4. Relating the three public clusters to additional variables regarding growth.

\subsection{Comparing clusters in the two surveys using a growth skepticism index}

The next step of the analysis is to bring together the two surveys and compare the clusters that appear similar (e.g. Green growth clusters in public and scientific opinion). We construct a composite index that represents low or high 'growth skepticism' expressed by the survey respondents. To this end, we considered agreement with items expressing a pro or anti-growth position. Some items had to be recoded (e.g. "Economic growth is necessary to finance environmental protection.") so that disagreement means high growth skepticism. The sum of all items were divided by the total number of items, resulting in a composite index that is also bound between 1 and 7, where larger values imply higher degrees of growth skepticism. We then compare clusters of both surveys how they score on this composite indicator, which is shown in Figure 5. The X-axis represents the composite indicator, while the color of the spheres is the same as in Section 3.2. Note that the item "Economic growth can be controlled 
by the government" was coded so that agreement with the statement is counted as expressing growth skepticism. This is a debatable choice and we therefore also considered a reverse coding, as illustrated by the white spheres in Figure 5.

A notable finding, apart from a much larger overall spread between the clusters in scientific opinion compared to public opinion, is that the Agrowth Pub cluster is closer to the Green growth Pub cluster, but not to its counterpart, that is, the Agrowth Sci cluster. Overall, these results suggest more diversity of opinion in the survey of scientists. The general public tends to be less skeptical about growth, with three clusters (on average) slightly below the average of the composite score. Nevertheless, these results should be analyzed in more detail as will be done in the following subsection. 


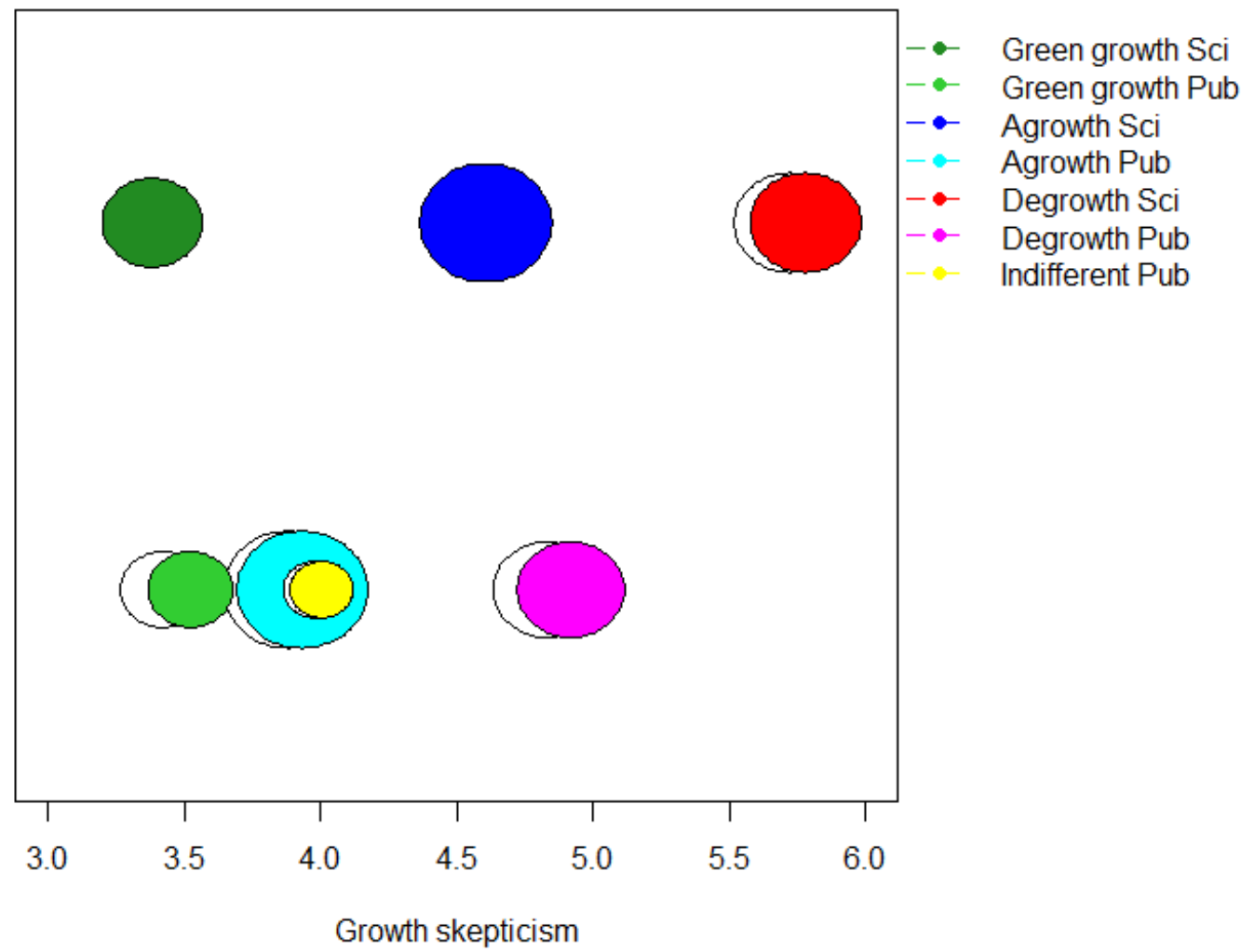

Figure 5. Clusters in public and scientific opinion survey viewed according to their average composite index of 'growth skepticism'.

Note: The size of a sphere represents the size of the associated cluster. The upper three spheres represent scientific opinion and the lower four - public opinion. If we consider the 'Governmental control' variable to have the opposite interpretation (not anti- but pro-growth), the positioning of the clusters would slightly change, as reflected by the white spheres. One can see that the positioning of public opinion clusters is more sensitive to interpretation of this variable. In the scientific opinion only the degrowth cluster moves slightly to the left.

\subsection{Comparing similar clusters between the two surveys on all questions}

A final step in the analysis is to compare the clusters of the two surveys on all survey items. Given that the Indifferent Pub cluster in public opinion is relatively small and lacks an equivalent cluster in scientific opinion, we decided to drop it from this part of the analysis. We will discuss a visual analysis presented in Figure 6, but note that formal statistical tests comparing the clusters can be found in Table A2 in the Appendix. The Green growth clusters, 
represented by the dark green (public opinion) and light green (scientific opinion) boxplots in Figure 6 have similar opinions on environmental protection, flawed welfare measure, full employment, life satisfaction, stability and techno fix. The scientists and the general public have diverging views on some environmental statements, such as development space and environmental damage, indicating that Green growth Sci is less concerned about environmental limits and damages of growth. The two clusters furthermore are at least two scale points apart on items like good life (scientists are undecided, public disagrees), income inequality (public agrees) and post-materialism (scientists agree). In sum, the Green growth $P u b$ cluster seems to be more associated with social and economic arguments in favour of growth, while Green growth Sci are more convinced about the compatibility of growth and environment.

How do the Agrowth clusters compare? We continue analyzing Figure 6, where blue represents public opinion and turquoise represents scientific opinion. Both clusters are similar in terms of opinion on income inequality, post-materialism and recovery. They are at least two scale points apart on environmental protection (public agrees, scientists disagree), excessive political attention (scientists agree), full employment (scientists agree, public disagree), good life (scientists agree), life satisfaction (scientists disagree, public agree) and techno fix (scientists disagree). Taken together, these results suggest that the Agrowth Sci cluster is overall more critical about growth, in particular regarding the technological potential to address environmental problems (note that scientists also somewhat agree with rebound). The Agrowth Pub cluster, in contrast is more optimistic regarding technological potential and questions the argument that good social welfare outcomes (e.g. full employment) can be achieved without growth.

Next, we examine the two Degrowth clusters, which are represented by the colours red (public opinion) and magenta (scientific opinion). They are similar on the issues of environmental protection, full employment, good life, governmental control, income 
inequality, public services, recovery and stability. They differ in terms of development space (scientists agree more than the public), energy rebound (scientists completely agree, while public opinion expresses no clear preference), environmental protection (scientists more strongly support the argument that growth is not necessary for protection of the environment), and techno fix (scientists disagree that technologies can solve all environmental problems). In addition, it is noteworthy that scientists are very clear that life satisfaction does not depend on growth, whereas opinions are more spread in the public cluster. One may conclude that both groups are skeptical about growth, but the scientists in this cluster are considerably more concerned about the incompatibility of growth and the environment than the general public. 

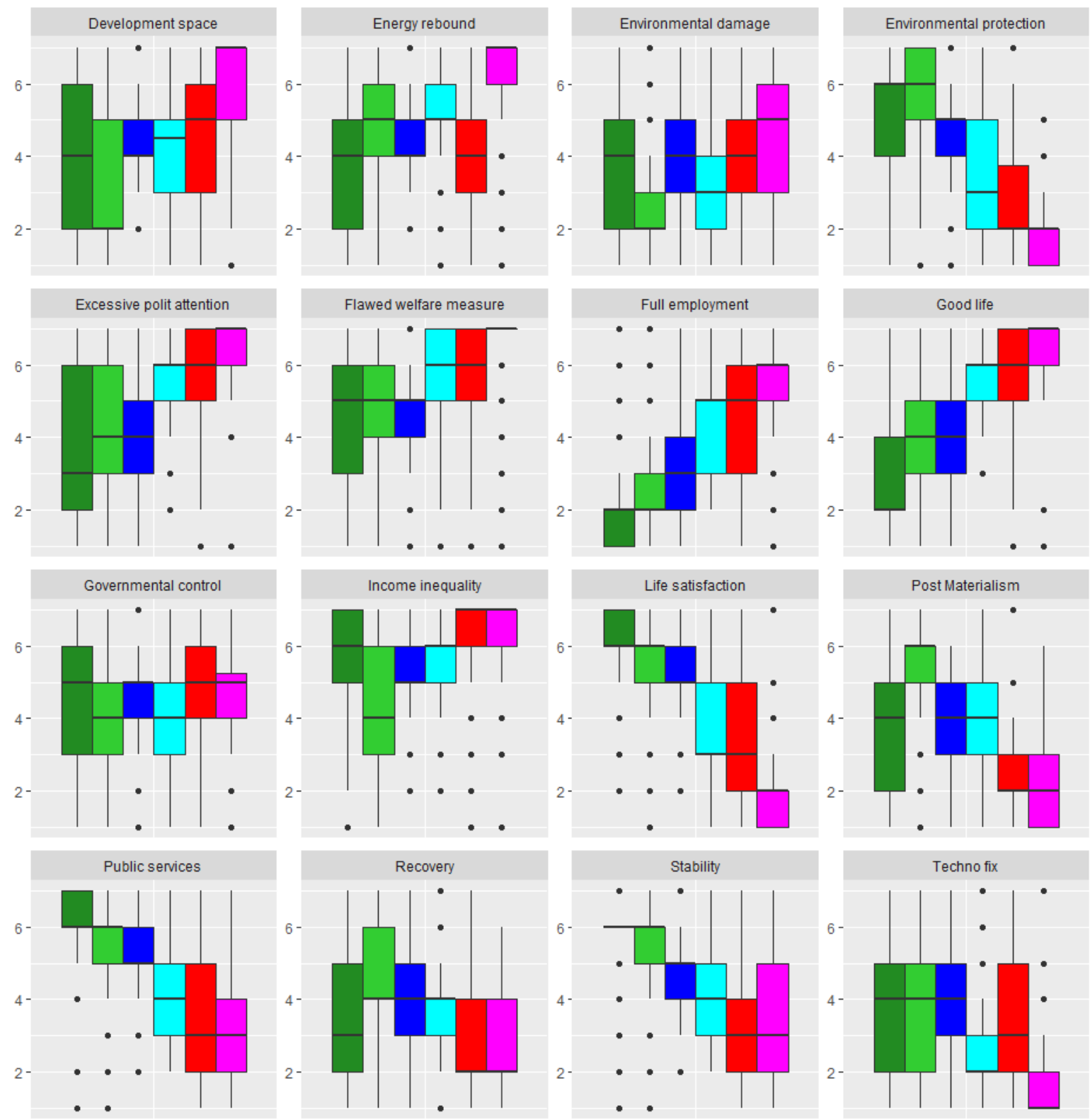

Green growth Sci

Green growth Pub Agrowth Pub Degrowth Pub

Figure 6. Comparing clusters across the scientific and public opinion surveys.

Note: Responses on the Y-axis range from 1 (completely disagree) to 7 (completely agree).

We further analyze how the clusters relate to additional variables that are present in both surveys, as shown in Figure 7. Three specific variables are of interest, capturing beliefs and preferences regarding economic growth: belief in an end of growth in the future, a preferred growth-environment position, and a preferred growth rate (see Figure A5 in the Appendix for 
three socio-demographic variables: age, gender and political orientation). As mentioned before, most noteworthy is that the scientific clusters relate more consistently to the additional variables about growth. For example, while the Degrowth Pub cluster has a preferred growth rate of around $2.5 \%$, the Degrowth Sci cluster lies around 0\%. With respect to the three sociodemographic variables, it is noteworthy that both Degrowth clusters were - compared to the Agrowth clusters - significantly more likely to be associated with more left-wing political orientation (Table 2). In addition, Green growth Sci, but not Green growth Pub, was significantly associated with more political right-wing orientation.

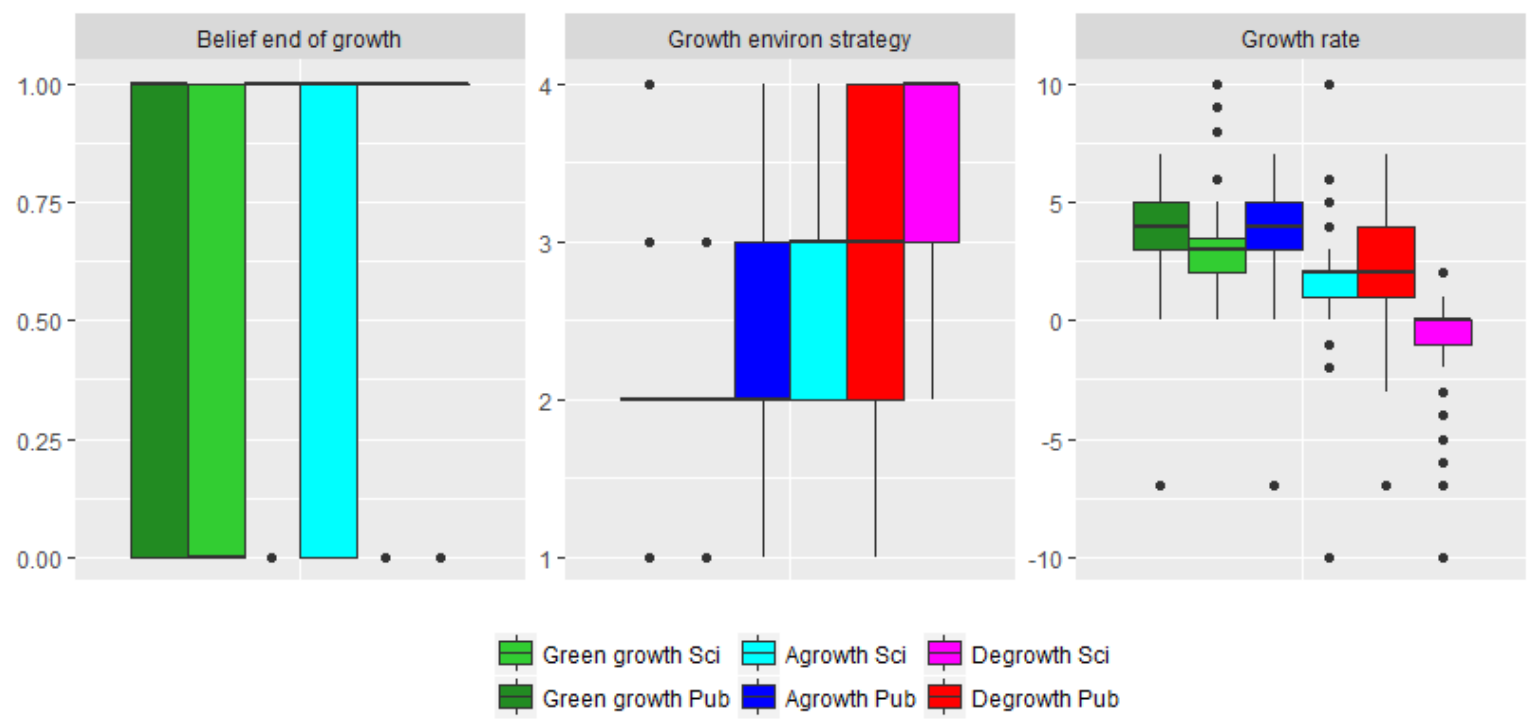

Figure 7. Comparing clusters across the scientific and public opinion surveys regarding the additional variables about growth.

\section{Conclusions}

This paper had the objective to identify and analyze opinion clusters in two surveys of public and scientific opinions in the debate on growth-versus-environment. This delivers four key findings. First, we find three opinion clusters in scientific opinion, which we labeled as Green growth, Agrowth and Degrowth. In public opinion, we find three clusters that are comparable to the three clusters in scientific opinion, as well as one additional, relatively small cluster that 
we interpret as a group of people who are undecided or indifferent about growth/environment. Second, clusters in the scientific opinion survey are systematically different on almost all main questions related to the growth-versus-environment debate, whereas in the public opinion survey such differences only apply to some questions. Third, the scientific opinion clusters are more consistently related to additional questions about growth. Most notably, the Green growth Sci cluster favours continuing with economic growth, the Agrowth Sci cluster favours ignoring it, while the Degrowth Sci cluster favours stopping it. Such consistent preferences could not be identified in public opinion, although the overall tendencies are similar. Fourth, when comparing clusters of both surveys on a composite score of growth skepticism, one sees that the clusters in the scientific opinion lie further apart, indicating stronger polarization compared to the public sample. That is, the Degrowth Sci cluster is considerably more skeptical about growth compared to Degrowth Pub cluster.

Overall, our results are somewhat consistent with a study for Canada (Tomaselli, 2017) which found that $41 \%$ of the study participants held pro-growth worldview, $23 \%$ held a proenvironment worldview (skepticism about indefinite growth and technology), and 36\% were in-between these two segments (no strong opinions about any issue). In our public opinion survey, the Green growth segment is also larger than the Degrowth one. The segments that are in-between these two groups, though, are even larger in our sample. In other words, it is only minorities that have relatively clear and consistent views on the growth-environment relationship, while a majority is undecided and emphasizes distinct issues. In any case, the important contribution of this study is to identify distinct clusters in the growth-versusenvironment debate, whereas the exact percentage of each of these is likely to differ across cultural contexts, as indicated by more general cross-country comparisons of environmental perceptions (e.g. Brechin and Bhandari, 2011).

The higher consistency and polarization among scientists compared to the general public may be an expression of different dimensions of attitude strength (Howe and Krosnick, 2017). 
Researchers are likely to be more personally involved in the issue and consider it more important, having, thus, more accessible memory of the relevant concepts and showing stronger emotions related to them. These factors cause attitudes to be more 'crystallized', indicating consistency and polarization. The latter imply that public opinion may be considerably less stable and can be more easily influenced, for instance, through communication.

In terms of policy, our findings suggest that a considerable part of the population exhibits skeptical views about growth. This evidence contradicts the common assumption of unequivocal public support for economic growth (Buch-Hansen, 2018) and is good news for policymakers who are critical of growth on a personal rather than party level (Rivera, 2017). It is, of course, debatable whether the Degrowth Pub cluster deserves its name, as it does not show such a consistent and intense opposition to growth compared to the scientific cluster. "Growth skeptics" could be a suitable alternative. But the choice of labels is difficult in any segmentation study. We think that the labels used here are generally meaningful as well as consistent with recent academic and public debates (e.g., van den Bergh and Kallis, 2012, Jakob and Edenhofer, 2012).

Several research implications follow from our findings. First, public opinion studies capturing views on growth/environment through single-item questions are recommended to use three (Green growth, Agrowth and Degrowth) instead of two (pro-growth/proenvironment) response options, confirming suggestions by earlier studies (Kaplowitz et al., 2013; Drews and van den Bergh, 2016). Next, future research could try to validate the present findings, notably whether segments differ in socio-demographic, attitudinal or behavioral respects, or whether or not the same or similar segments are found in distinct cultural contexts. A final suggestion is to employ the developed clusters to study the role of public perceptions in climate-economy modelling (as done by Geisendorf 2016). 
Acknowledgements: We thank three anonymous reviewers for their useful comments. This study has received funding through an ERC Advanced Grant from the European Research Council (ERC) under the European Union's Horizon 2020 research and innovation program (grant agreement $\mathrm{n}^{\circ}$ 741087). IS also acknowledges RFBR grant №18-010-01190.

\section{References}

Bacher, J., Wenzig, K. \& Vogler, M. (2004). SPSS twostep cluster: A first evaluation. (Arbeits- und Diskussionpapiere. 2, 2) Erlange-Nurnberg, University of FriedrichAlexander, Chair of Sociology (retrieved August 25, 2007). Available from: http://www.soziologie.wiso.uni-erlangen.de/publikationen/a-u-d-papiere.shtml.

Blendon, R.J., Benson, J.M., Brodie, M., Morin, R., Altman, D.E., Gitterman, D., Brossard, M., James, M., 1997. Bridging the Gap between the Public's and Economists' Views of the Economy. Journal of Economic Perspectives 11, 105-118. https://doi.org/10.1257/jep.11.3.105

Brechin, S.R., Bhandari, M., 2011. Perceptions of climate change worldwide. Wiley Interdisciplinary Reviews: Climate Change 2, 871-885. https://doi.org/10.1002/wcc.146

Buch-Hansen, H., 2018. The Prerequisites for a Degrowth Paradigm Shift: Insights from Critical Political Economy. Ecological Economics 146, 157-163. https://doi.org/10.1016/j.ecolecon.2017.10.021

Drews, S., Antal, M., van den Bergh, J.C.J.M., 2018. Challenges in Assessing Public Opinion on Economic Growth Versus Environment: Considering European and US Data. Ecological Economics 146, 265-272. https://doi.org/10.1016/j.ecolecon.2017.11.006

Drews, S., van den Bergh, J.C.J.M., 2017. Scientists' views on economic growth versus the environment: a questionnaire survey among economists and non-economists. Global Environmental Change 46, 88-103. https://doi.org/10.1016/j.gloenvcha.2017.08.007

Drews, S., van den Bergh, J.C.J.M., 2016. Public views on economic growth, the environment and prosperity: Results of a questionnaire survey. Global Environmental Change 39, 1-14. https://doi.org/10.1016/j.gloenvcha.2016.04.001

Eversberg, D., Schmelzer, M., 2017. The degrowth spectrum: Convergence and divergence within a diverse and conflictual alliance. Environmental Values.

Geisendorf, S., 2016. The impact of personal beliefs on climate change: the "battle of perspectives" revisited. Journal of Evolutionary Economics 26, 551-580. https://doi.org/10.1007/s00191-016-0461-9

Hine, D.W., Reser, J.P., Morrison, M., Phillips, W.J., Nunn, P., Cooksey, R., 2014. Audience segmentation and climate change communication: conceptual and methodological considerations: Audience segmentation and climate change communication. Wiley Interdisciplinary Reviews: Climate Change 5, 441-459. https://doi.org/10.1002/wcc.279

Howe, L.C., and J.A. Krosnick (2017). Attitude Strength. Annual Review of Psychology 68:327-351.

Illge, L., Schwarze, R., 2009. A matter of opinion-How ecological and neoclassical environmental economists and think about sustainability and economics. Ecological Economics 68, 594-604. https://doi.org/10.1016/j.ecolecon.2008.08.010

Jackson, T., 2009. Prosperity Without Growth: Economics for a Finite Planet. Routledge. 
Jakob, M., Edenhofer, O., 2014. Green growth, degrowth, and the commons. Oxf. Rev. Econ. Policy 30, 447-468. doi:http://dx.doi.org/10.1093/oxrep/gru026.

Kaplowitz, M.D., Lupi, F., Yeboah, F.K., Thorp, L.G., 2013. Exploring the middle ground between environmental protection and economic growth. Public Understanding of Science 22, 413-426. https://doi.org/10.1177/0963662511424545

Kubiszewski, I., Costanza, R., Franco, C., Lawn, P., Talberth, J., Jackson, T., Aylmer, C., 2013. Beyond GDP: Measuring and achieving global genuine progress. Ecological Economics 93, 57-68. https://doi.org/10.1016/j.ecolecon.2013.04.019

Linzer, D.A., Lewis, J.B., 2011, poLCA: An R Package for Polytomous Variable Latent Class Analysis. Journal of Statistical Software, 42(10), 1-29. URL http://www.jstatsoft.org/v42/i10/

Maibach, E.W., Leiserowitz, A., Roser-Renouf, C., Mertz, C.K., 2011. Identifying LikeMinded Audiences for Global Warming Public Engagement Campaigns: An Audience Segmentation Analysis and Tool Development. PLoS ONE 6, e17571. https://doi.org/10.1371/journal.pone.0017571

McCutcheon, A.L., 1987, Latent Class Analysis, Beverly Hills, CA: Sage Publications, http://dx.doi.org/10.4135/9781412984713

Moloney, G., Leviston, Z., Lynam, T., Price, J., Stone-Jovicich, S., Blair, D., 2014. Using social representations theory to make sense of climate change: what scientists and nonscientists in Australia think. Ecology and Society 19. https://doi.org/10.5751/ES06592-190319

Mooij, R.A.D., Bergh, J.C.J.M. van D., 2002. Growth and the Environment in Europe: A Guide to the Debate. Empirica 29, 79-91. https://doi.org/10.1023/A:1015642326265

Nylund K. L., Asparouhov T., Muthén B. O., 2007, Deciding on the number of classes in latent class analysis and growth mixture modeling: a Monte Carlo simulation study. Structural Equation Modeling 14(4): 535-569.

O'Neill, D.W., 2012. Measuring progress in the degrowth transition to a steady state economy. Ecological Economics 84, 221-231. https://doi.org/10.1016/j.ecolecon.2011.05.020

Poortinga, W., Darnton, A., 2016. Segmenting for sustainability: The development of a sustainability segmentation model from a Welsh sample. Journal of Environmental Psychology 45, 221-232. https://doi.org/10.1016/j.jenvp.2016.01.009

Ripple, W.J., Wolf, C., Newsome, T.M., Galetti, M., Alamgir, M., Crist, E., Mahmoud, M.I., Laurance, W.F., 2017. World Scientists' Warning to Humanity: A Second Notice. BioScience. https://doi.org/10.1093/biosci/bix125

Rivera, M., 2017. Growth in parliament: Some notes on the persistence of a dogma'. Futures. https://doi.org/10.1016/j.futures.2017.09.002

Sapienza, P., Zingales, L., 2013. Economic Experts versus Average Americans. American Economic Review 103, 636-642. https://doi.org/10.1257/aer.103.3.636

Sturgis, P., Roberts, C., Smith, P., 2014. Middle Alternatives Revisited: How the neither/nor Response Acts as a Way of Saying "I Don't Know"? Sociological Methods \& Research 43, 15-38. https://doi.org/10.1177/0049124112452527

Tomaselli, F., 2017. Towards an ecological economics paradigm: An exploration of mental models and public perceptions. University of British Columbia, Vancouver.

van den Bergh, J.C.J.M., Kallis, G., 2012. Growth, A-Growth or Degrowth to Stay within Planetary Boundaries? Journal of Economic Issues 46, 909-920. https://doi.org/10.2753/JEI0021-3624460404

Vermunt, J.K. and Magidson, J., 2004, Latent class analysis. In: M.S. Lewis-Beck, A. Bryman, and T.F. Liao (eds.), The Sage Encyclopedia of Social Sciences Research Methods, 549-553. Thousand Oaks, CA: Sage Publications. 
Victor, P.A., Dolter, B. (Eds.), 2017. Handbook on growth and sustainability. Edward Elgar Publishing, Cheltenham, UK.

Ward, J.D., Sutton, P.C., Werner, A.D., Costanza, R., Mohr, S.H., Simmons, C.T., 2016. Is Decoupling GDP Growth from Environmental Impact Possible? PLOS ONE 11, e0164733. https://doi.org/10.1371/journal.pone.0164733

\section{Appendix.}

Table A1. Kolmogorov-Smirnov and Wilcox tests for missing observations in the scientific opinion survey

\begin{tabular}{|l|r|r|r|r|r|}
\hline Variable & \multicolumn{1}{|c|}{$\begin{array}{c}\text { Mean in the } \\
\text { obs }\end{array}$} & $\begin{array}{c}\text { sample of } \\
\text { missings }\end{array}$ & $\begin{array}{c}\text { Mean in the } \\
\text { whole sample }\end{array}$ & $\begin{array}{c}\text { Kolmogorov- } \\
\text { Smirnov test } \\
\text { p value }\end{array}$ & $\begin{array}{c}\text { Wilcox test } \\
\text { p value }\end{array}$ \\
\hline Environmental protection & 131 & 3.98 & 3.84 & 0.81 & 0.49 \\
\hline Income inequality & 134 & 5.42 & 5.26 & 0.68 & 0.40 \\
\hline Life satisfaction & 132 & 3.66 & 3.79 & 0.98 & 0.44 \\
\hline Development space & 132 & 4.28 & 4.41 & 0.99 & 0.47 \\
\hline Techno fix & 134 & 2.87 & 2.71 & 0.97 & 0.38 \\
\hline Excessive polit attention & 131 & 5.28 & 5.36 & 1.00 & 0.77 \\
\hline Post materialism & 134 & 4.07 & 4.08 & 0.86 & 0.93 \\
\hline Flawed welfare measure & 129 & 5.60 & 5.69 & 1.00 & 0.66 \\
\hline Stability & 125 & 4.43 & 4.35 & 0.86 & 0.58 \\
\hline Environmental damage & 137 & 3.33 & 3.30 & 1.00 & 0.97 \\
\hline Recovery & 92 & 3.88 & 3.64 & 0.48 & 0.11 \\
\hline Full employment & 111 & 4.20 & 4.11 & 0.86 & 0.59 \\
\hline Public services & 128 & 4.38 & 4.35 & 1.00 & 0.74 \\
\hline Energy rebound & 112 & 5.57 & 5.47 & 0.96 & 0.27 \\
\hline Governmental control & 122 & 4.17 & 4.14 & 0.80 & 0.67 \\
\hline Good life & 125 & 5.30 & 5.27 & 1.00 & 0.70 \\
\hline Belief end of growth & 92 & 0.54 & 0.57 & 1.00 & 0.70 \\
\hline Growth environ strategy & 124 & 2.70 & 2.71 & 1.00 & 0.80 \\
\hline Political orientation & 131 & 3.01 & 2.97 & 1.00 & 0.64 \\
\hline Gender & 140 & 0.29 & 0.24 & 0.90 & 0.19 \\
\hline Age & 137 & 44.28 & 45.37 & 0.29 & 0.27 \\
\hline Growth rate & 69 & 1.57 & 1.59 & 0.98 & 0.73 \\
\hline
\end{tabular}

Table A2. Comparisons of cluster within and between surveys

\begin{tabular}{|c|c|c|c|c|c|c|c|c|c|c|c|c|}
\hline \multirow[b]{2}{*}{ Variable } & \multicolumn{3}{|c|}{$\begin{array}{c}\text { Scientific opionion } \\
\text { survey }\end{array}$} & \multicolumn{6}{|c|}{ Public opinion survey } & \multicolumn{3}{|c|}{$\begin{array}{c}\text { Pairwise comparison } \\
\text { between surveys }\end{array}$} \\
\hline & $1 \& 2$ & $1 \& 3$ & $2 \& 3$ & $1 \& 2$ & $1 \& 3$ & $1 \& 4$ & $2 \& 3$ & $2 \& 4$ & $3 \& 4$ & $1 \& 1$ & $2 \& 2$ & $3 \& 3$ \\
\hline
\end{tabular}




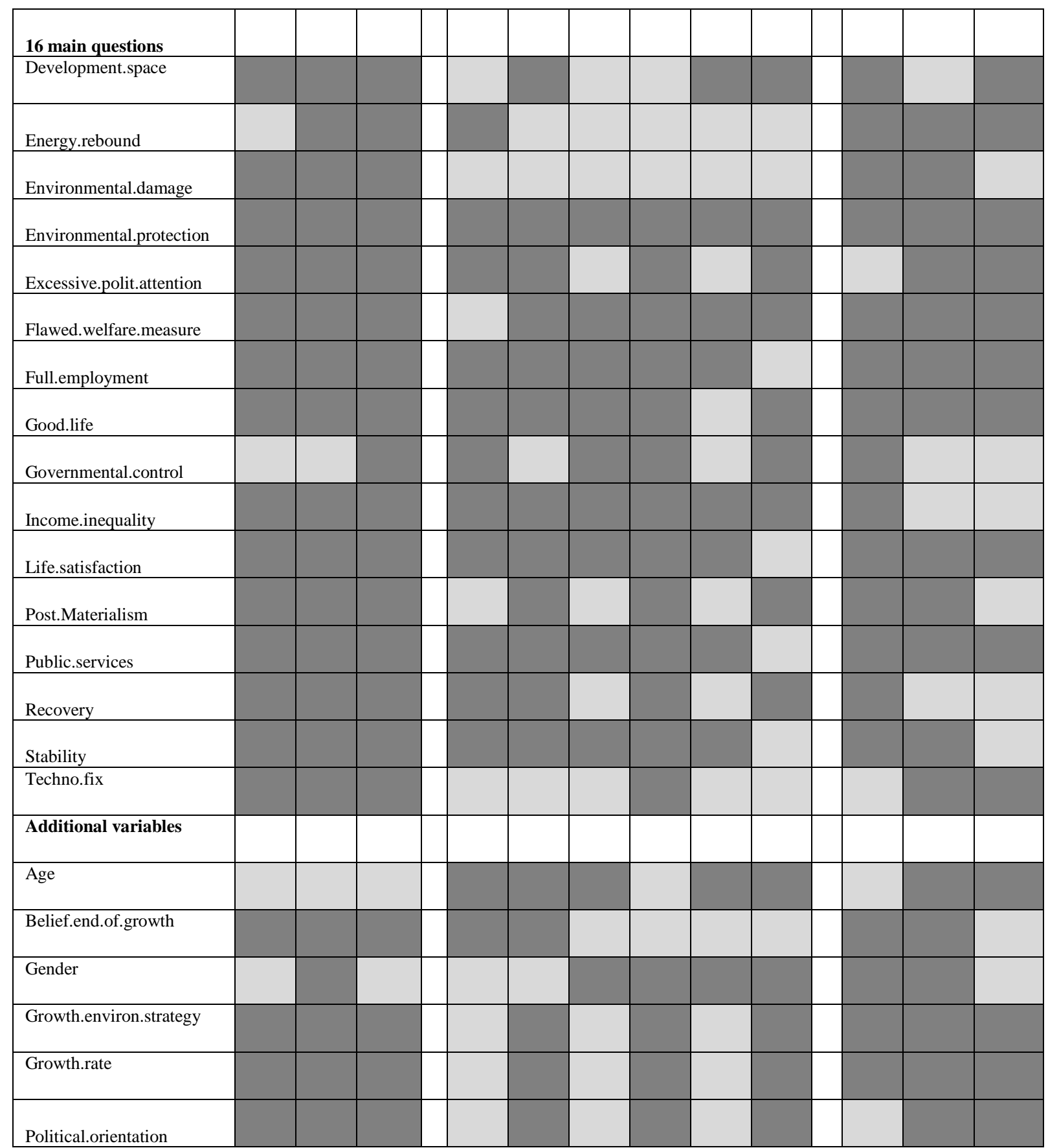

Note: in the table results of the Krushkal-Wallis rank sum test with bonferroni correction of p-values at the $1 \%$ significance value are presented. If the two clusters are significantly different according to the test, the entry has a dark shading, while if the two clusters are not significantly different on the variable of interest, the entry has light shading. The left block of the column presents results for clusters generated in the scientific opinion survey, the mid block - for clusters in the public opinion survey, while the right block compares clusters with seemingly similar attitude between the two surveys. 1=Green growth, 2=Agrowth, 3=Degrowth, 4=Indifferent. 


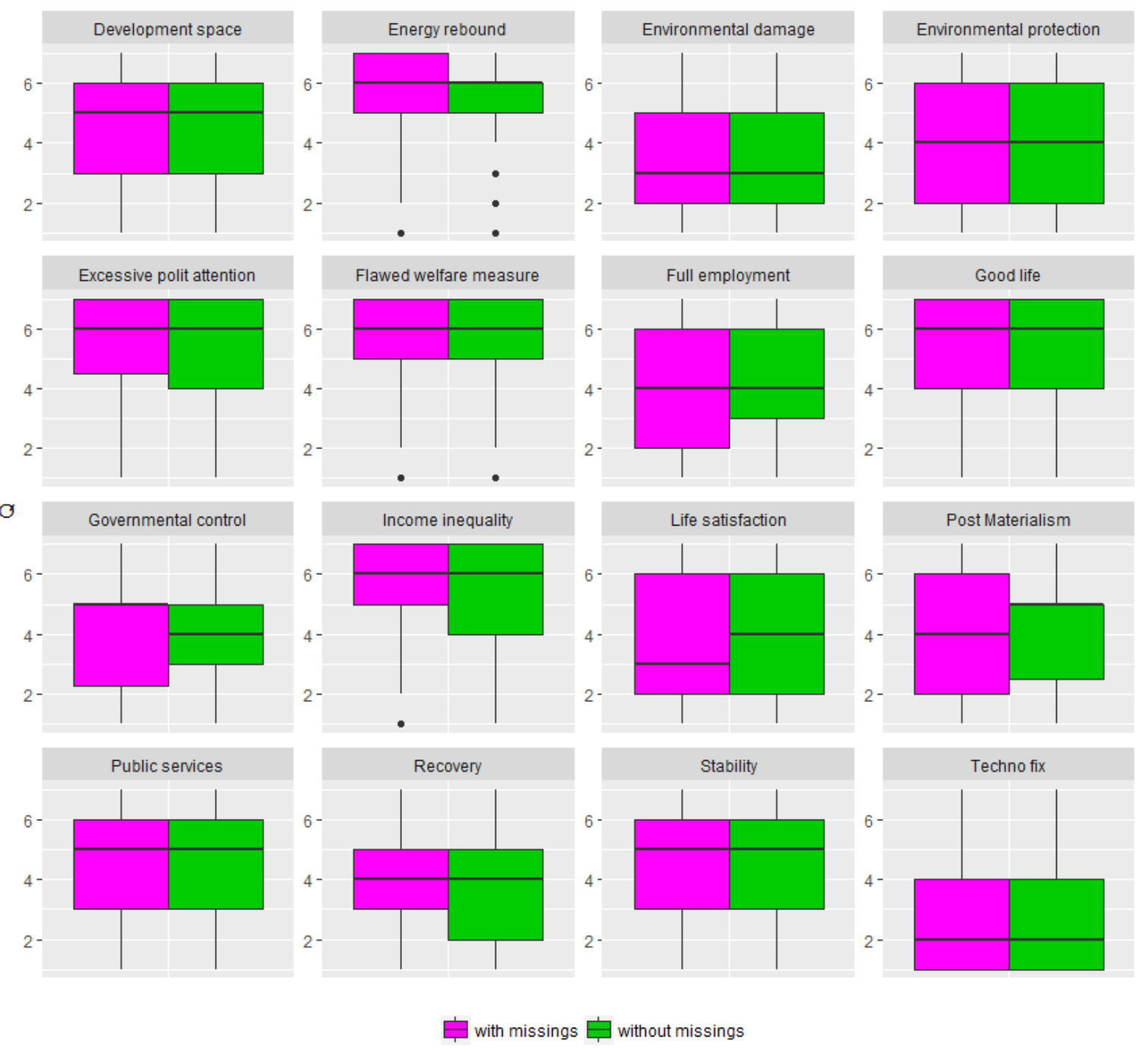

Figure A1. Distribution of observations with missings compared to those without missings over the 16 questions concerning the growth-vs-environment debate in the scientific opinion survey. 


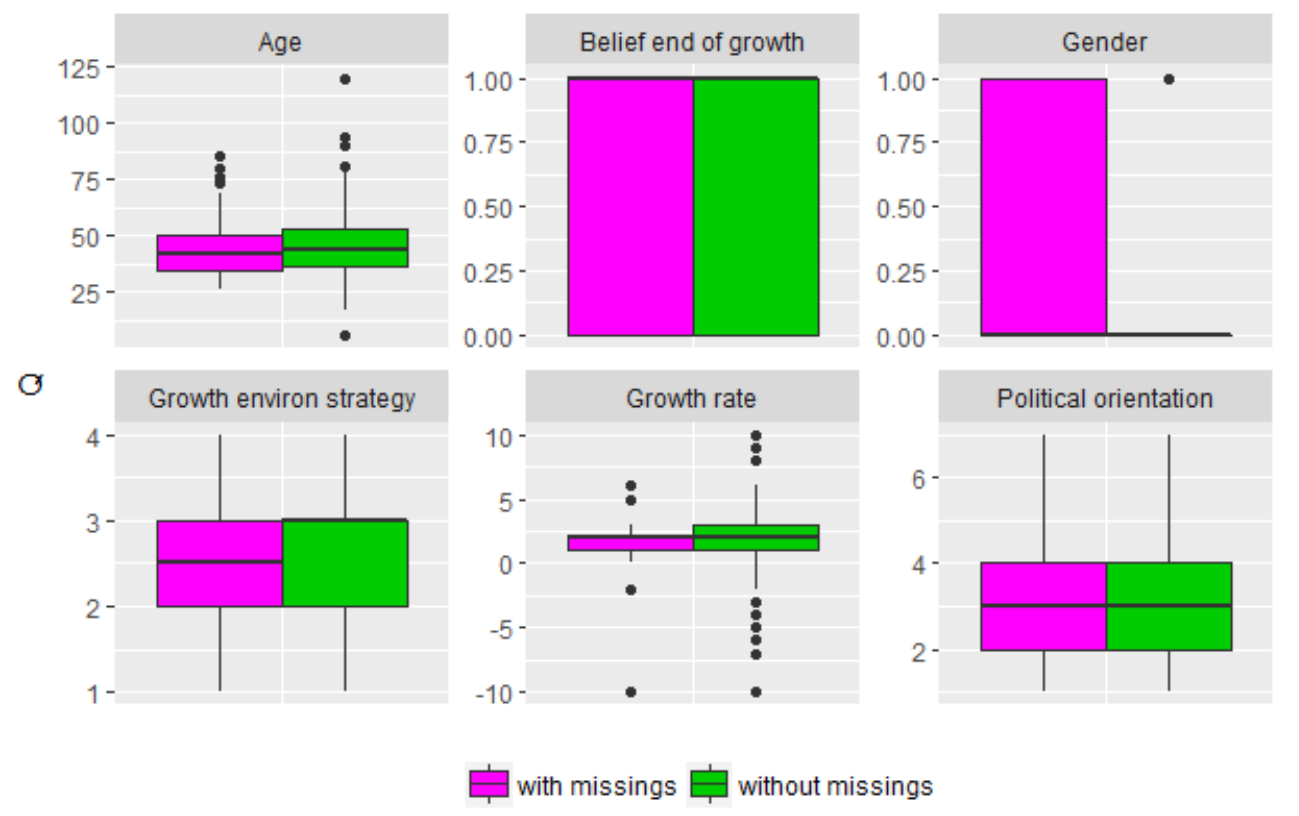

Figure A2. Distribution of observations with missings compared to those without missings over sociodemographic and other questions in the scientific opinion survey.
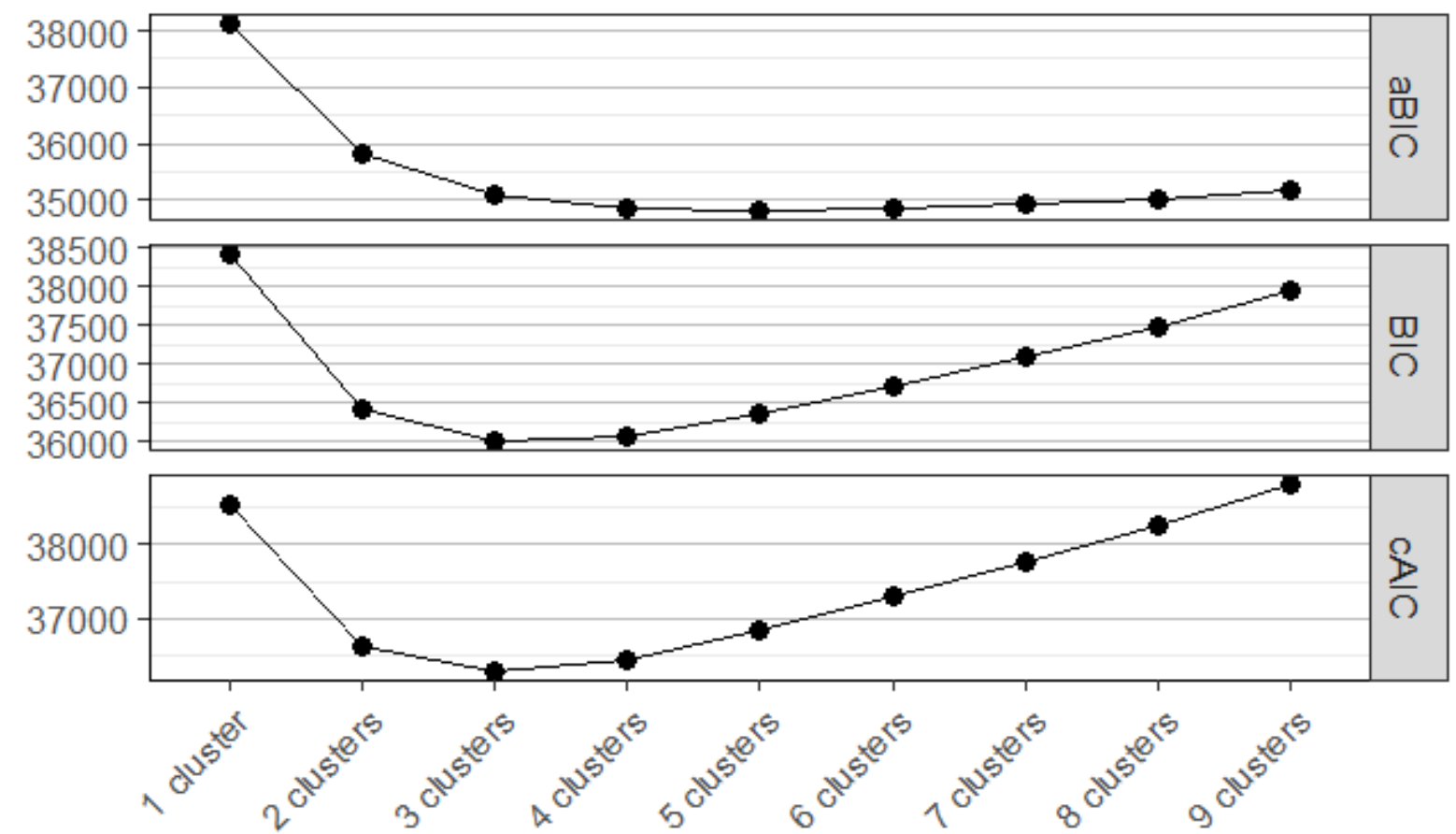

Figure A3. Plot of information criteria for 1- to 9- cluster solutions for the scientific opinion survey. 

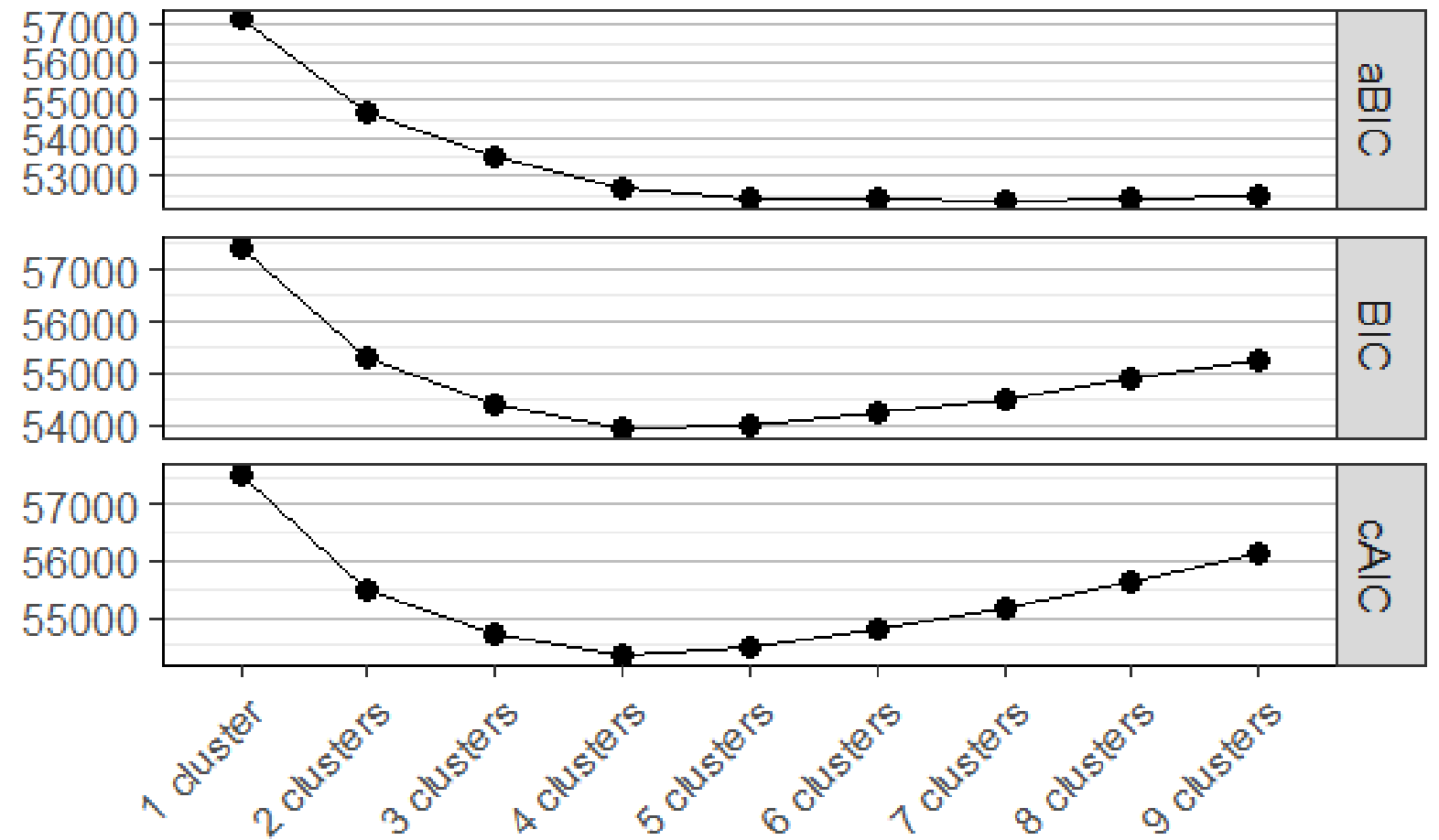

Figure A4. Plot of information criteria for 1- to 9- cluster solutions for the public opinion survey.

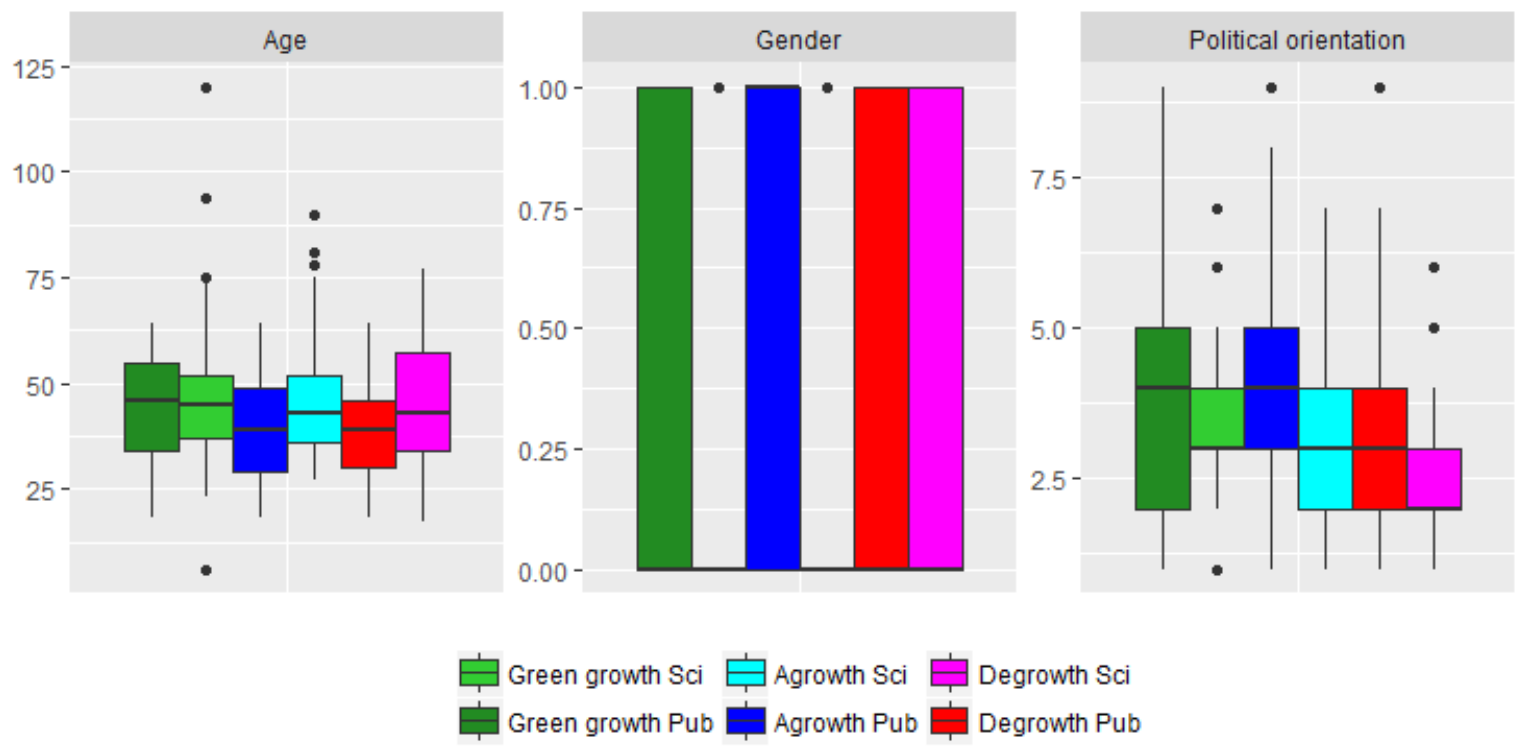

Figure A5. Relating clusters of the scientific and public opinion surveys to the sociodemographic characteristics. 